\title{
Selecting a healthy diet score: lessons from a study of diet and health in early old age (the Boyd Orr cohort)
}

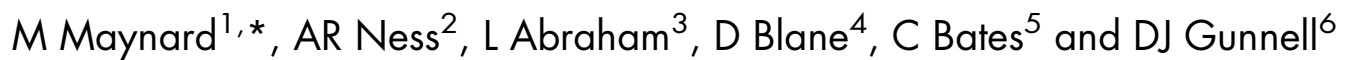 \\ 'MRC Social and Public Health Sciences Unit, University of Glasgow, 4 Lilybank Gardens, Glasgow G12 8RZ, \\ UK: ${ }^{2}$ Department of Paediatric and Perinatal Epidemiology, University of Bristol, Bristol, UK: ${ }^{3}$ Outcomes Research, \\ Sandwich, UK: ${ }^{4}$ Department of Social Science and Medicine, Imperial College of Science, Technology and \\ Medicine, London, UK: ${ }^{5}$ MRC Human Nutrition Research, Cambridge, UK: ${ }^{6}$ Department of Social Medicine, \\ University of Bristol, Bristol, UK
}

Submitted 28 September 2001: Accepted 22 September 2004

\begin{abstract}
Objectives: To describe the selection and modification of an appropriate diet score to assess diet quality in early old age.

Design and setting: Cross-sectional analyses of the Boyd Orr cohort - a long-term follow-up of men and women whose families took part in a survey of diet and health in pre-war Britain. Dietary data were obtained from a 113-item food-frequency questionnaire. A nine-item Healthy Diet Indicator (HDI) developed by Huijbregts and colleagues was identified from the literature and modified because some dietary variables were unavailable and to accord more closely with recommendations of the UK Committee on Medical Aspects of Food Policy.

Subjects: In total, 1475 traced, surviving cohort members aged 60 years and over. Results: Modification resulted in a 12-item Healthy Diet Score (HDS). We found that about half the variation in the HDS was explained by variation in the HDI $(r=0.71)$. There was, however, little misclassification of subjects $(<10 \%)$ into extreme thirds of the distribution by the HDS compared with the HDI. Items of the score most strongly correlated with overall score were saturated fat $(r=-0.57)$, red meat $(r=-0.46)$, dietary fibre $(r=0.58)$, fruit and vegetables $(r=0.54)$ and percentage energy from carbohydrates $(r=0.51)$. Modifying existing items had greater impact on agreement between HDI and HDS than the addition of new items.

Conclusions: The selection and modification of diet scores is more complicated than often assumed. Furthermore, modest changes to an existing score can produce a score that is different from the original, and although it was not possible to test this issue, it may no longer predict subsequent health experience.
\end{abstract}

Keywords Dietary patterns Healthy diet score
Epidemiological studies of the association between diet and disease have tended to focus on specific constituentdisease associations such as the protective role of vitamin C intake against cancer risk $^{1}$ or the role of fats in cardiovascular disease $\mathrm{e}^{2,3}$. Such an approach is potentially important in advancing understanding of the aetiology and pathogenesis of disease processes. It is less valuable, however, for policy formulation, where some quantification of the overall health benefits of a dietary pattern is required. There is thus a need to complement the constituent-disease approach by describing whole diet patterns, their determinants and their relation to overall health.

A number of different techniques have been employed to describe dietary patterns in populations ${ }^{4-6}$. One approach is to use multivariate techniques such as discriminant analysis $^{7}$, factor analysis ${ }^{8-10}$, principal components analysis $^{11}$ or cluster analysis ${ }^{12-14}$ to identify dietary patterns based on the dietary data itself. The disadvantage of these techniques is that the data-derived patterns may be population-specific and not necessarily related to health ${ }^{15}$. An alternative approach is to apply a scoring system to derive a diet quality score. Scores have been described based on the absence of dietary deficiency, comparison with recommendations for a healthy diet, and similarities with other diets such as the Mediterranean or Japanese $\operatorname{diet}^{5}$. This latter approach potentially allows the use of scores across different populations that have meaning in terms of health.

A number of different scores based on guidelines for an optimum diet have been derived and used ${ }^{5,16-21}$. Unfortunately, the rationale for these scores and the weightings employed are seldom described ${ }^{6}$. Furthermore, few scores have been shown to be predictive of 
subsequent good health - the ultimate test of their validity $^{14,22-26}$. The selection of a healthy diet score for use in epidemiological studies is therefore not straightforward. There has been similar debate regarding the scoring systems used to assess the quality of clinical trials ${ }^{27}$. Here we describe the process we used to select and adapt an existing score. The score was subsequently used to assess diet quality in a study which examined the social, economic and lifestyle factors that influenced healthy diet at post-retirement age in a British population.

\section{Methods}

\section{The Boyd Orr cohort}

The population for which we wanted to select a score comprised the surviving members of the Boyd Orr cohort - a long-term follow-up study based on about 5000 men and women who as children took part in a survey of family diet and health in pre-war (1937-39) Britain ${ }^{28}$. In 1997/98 all 3182 traced surviving study members, then aged $60-80$ years, were sent a health, diet and lifestyle questionnaire. Questionnaires were returned by 1647 respondents (52\% response rate). Included in the diet and health questionnaire was a 113-item modified version of the foodfrequency questionnaire (FFQ) developed for use in the Cambridge arm of the European Investigation of Cancer and Nutrition ${ }^{29}$. FFQs suitable for analysis were returned by 1475 people. Portion size was assigned to each FFQ item using published standard portion size data ${ }^{30}$. Daily intakes of energy and a number of nutrients were calculated using a computerised suite of programs based on food tables in McCance \& Widdowson's The Composition of Foods ${ }^{31}$ and supplements. Daily consumption of foods was estimated. The relevant food groups here were fruit and vegetables based on the sum of 30 FFQ items, pulses and nuts based on three items, fish based on three items, and red meat and meat products based on the sum of nine FFQ items.

\section{Selection of a bealthy diet score}

Our intention was first to use a diet score to assess how well the diet of the respondents complied with current advice on healthy eating as recommended by the UK Committee on Medical Aspects of Food Policy $(\mathrm{COMA})^{32,33}$, and second to investigate factors influencing diet quality. We decided to try and find an existing score that had been shown to predict subsequent health to ensure that we used a validated instrument that would allow comparison with other studies. We searched the electronic databases MEDLINE and EMBASE and located additional references from relevant publications (such as the review by $\mathrm{Kant}^{5}$ ). The 'Healthy Diet Indicator' (HDI) devised by Huijbregts et al. ${ }^{14}$ was the only score that met our specifications, in that it was based on guidelines similar to the current COMA guidelines and had been shown to predict mortality in a group of middle-aged and elderly Europeans. It is a nine-item score (see Table 1) based on World Health Organization (WHO) healthy diet recommendations ${ }^{34}$. A score of 1 is attributed to an individual if their diet meets the recommendations for a component or 0 if it does not. The maximum score is therefore 9 .

\section{Modification of the HDI}

We made a number of modifications to the index. First, we were forced to make some changes because we did not

Table 1 Cut-off points for the original Healthy Diet Indicator (HDI) and the modified Healthy Diet Score (HDS) used in the study of Boyd Orr cohort members (672 males $(\mathrm{M})$, 803 females $(\mathrm{F})$ )

\begin{tabular}{|c|c|c|c|c|c|c|}
\hline \multicolumn{3}{|c|}{ HDI } & \multicolumn{4}{|c|}{ HDS } \\
\hline \multirow[b]{2}{*}{ Index items } & \multicolumn{2}{|c|}{ Cut-off values } & \multirow[b]{2}{*}{ Index items } & \multicolumn{2}{|c|}{ Cut-off values } & \multirow{2}{*}{$\begin{array}{l}\% \text { of cohort } \\
\text { scoring } 1\end{array}$} \\
\hline & Score 1 & Score 0 & & Score 1 & Score 0 & \\
\hline $\begin{array}{l}\text { 1. Saturated fatty acids } \\
\text { (\% energy intake) }\end{array}$ & $0-10$ & $>10$ & $\begin{array}{l}\text { 1. Saturated fatty acids } \\
\text { (\% energy intake) }\end{array}$ & $0-10$ & $>10$ & $M=19, F=22$ \\
\hline $\begin{array}{l}\text { 2. Polyunsaturated fatty acids } \\
\text { (\% energy intake) }\end{array}$ & $3-7$ & $<3$ or $>7$ & $\begin{array}{l}\text { 2. Polyunsaturated fatty acids } \\
(\% \text { energy intake })^{\star}\end{array}$ & $6-10$ & $<6$ or $>10$ & $M=38, F=37$ \\
\hline 3. Protein (\% energy intake) & $10-15$ & $<10$ or $>15$ & 3. Protein (\% energy intake) & $10-15$ & $<10$ or $>15$ & $M=45, F=36$ \\
\hline $\begin{array}{l}\text { 4. Complex carbohydrates } \\
\text { (\% energy intake) }\end{array}$ & $50-70$ & $<50$ or $>70$ & $\begin{array}{l}\text { 4. Total carbohydrates } \\
(\% \text { energy intake })^{\star}\end{array}$ & $50-70$ & $<50$ or $>70$ & $M=41, F=52$ \\
\hline 5. Dietary fibre $(\mathrm{g})$ & $27-40$ & $<27$ or $>40$ & 5. Dietary fibre $(\mathrm{g})^{*}$ & $18-32$ & $<18$ or $>32$ & $M=47, F=51$ \\
\hline 6. Fruit and vegetables (g) & $\geq 400$ & $<400$ & 6. Fruit and vegetables $(\mathrm{g})$ & $\geq 400$ & $<400$ & $M=51, F=67$ \\
\hline 7. Pulses, nuts, seeds (g) & $\geq 30$ & $<30$ & 7. Pulses and nuts $(\mathrm{g})^{\star}$ & $\geq 30$ & $<30$ & $M=29, F=22$ \\
\hline $\begin{array}{l}\text { 8. Monosaccharides and } \\
\text { disaccharides } \\
\text { (\% total energy intake) }\end{array}$ & $0-10$ & $>10$ & $\begin{array}{l}\text { 8. Total non-milk extrinsic } \\
\text { sugars } \\
\text { (\% total energy intake) }\end{array}$ & $0-10$ & $>10$ & $\mathrm{M}=41, \mathrm{~F}=44$ \\
\hline \multirow[t]{2}{*}{ 9. Cholesterol (mg) } & $0-300$ & $>300$ & $\begin{array}{l}\text { 9. Cholesterol }(\mathrm{mg})^{*} \\
\text { 10. Fish }(\mathrm{g})^{*} \\
\text { 11. Red meat and } \\
\text { meat products }(\mathrm{g})^{*}\end{array}$ & $\begin{array}{l}0-245 \\
\geq 32 \\
\geq 90\end{array}$ & $\begin{array}{l}>245 \\
<32 \\
>90\end{array}$ & $\begin{array}{l}M=38, F=44 \\
M=32, F=38 \\
M=52, F=64\end{array}$ \\
\hline & & & 12. Calcium $(\mathrm{mg})^{*}$ & $\geq 700$ & $<700$ & $M=85, F=86$ \\
\hline
\end{tabular}

${ }^{\star}$ Modified or additional items. 
have comparable dietary data. Total carbohydrates replaced complex carbohydrates; and total non-milk extrinsic sugars replaced monosaccharides and disaccharides. 'Seed' consumption was not measured on the FFQ completed by the Boyd Orr cohort members and was therefore not included in the 'pulses, nuts and seeds' item. Second, we made some changes to comply more closely with COMA recommendations, where they differed from the WHO guidelines used in the original score. To comply with the most recently available COMA recommendations ${ }^{32,33}$ in our study population of older people, fish, red meat and calcium were added to the score. We also altered the cut-off points for percentage of energy from polyunsaturated fats, daily dietary fibre (non-starch polysaccharides) intake and daily cholesterol intake. Two factors that cannot accurately be derived from the FFQ data were sodium and trans-fatty acids, which were also not included in the score. The resulting 12-item index (renamed the Healthy Diet Score; HDS) and the original nine-item index are shown in Table 1. Using descriptive statistics and Spearman's rank correlation coefficients, we examined the characteristics of the new diet score and compared it with the original score.

\section{Results}

\section{Characteristics of the modified HDS}

The modified HDS was normally distributed. The scores ranged from 1 to 10 for men and from 1 to 11 for women. The mean score was 5.19 among the men and 5.63 for women.

\section{Comparison of the new and modified diet scores}

The original HDI produced a lower average score, with a mean score of 3.4 in men and 3.6 in women and a range of $0-8$. This is to be expected as the original score has nine items compared with the 12 of the modified score. Characteristics of the sample are shown in Table 2.

The Spearman's rank correlation between the two scores was 0.70 for men and 0.72 for women. Therefore,

Table 2 Demographic, lifestyle and socio-economic characteristics of the Boyd Orr study members

\begin{tabular}{|c|c|c|}
\hline & $\begin{array}{c}\text { Males } \\
(n=672)\end{array}$ & $\begin{array}{l}\text { Females } \\
(n=803)\end{array}$ \\
\hline Age (years), mean (SD) & $66.4(4.4)$ & $66.4(4.6)$ \\
\hline Housing tenure (\% owner occupiers) & 79 & 74 \\
\hline Social class (\% I-III non-manual) & 34 & 41 \\
\hline Living alone (\%) & 10 & 27 \\
\hline $\begin{array}{l}\text { Self-reported general health - } \\
\text { very good } / \text { good }(\%)\end{array}$ & 66 & 68 \\
\hline Current smokers (\%) & 24 & 21 \\
\hline BMI $\left(\mathrm{kg} \mathrm{m}^{-2}\right)$, mean (SD) & $26.1(3.4)$ & $26.2(4.5)$ \\
\hline Obese $\left(\mathrm{BMI} \geq 30 \mathrm{~kg} \mathrm{~m}^{-2}\right)(\%)$ & 13 & 18 \\
\hline Energy intake (MJ day $\left.{ }^{-1}\right)$, mean (SD) & $9.70(3.16)$ & $9.27(3.29)$ \\
\hline
\end{tabular}

SD - standard deviation; BMI - body mass index.
Table 3 Comparison of subjects' ranking (numbers and row percentages) in thirds of the original Healthy Diet Indicator (HDI) and the modified Healthy Diet Score (HDS)

\begin{tabular}{lcccc}
\hline & \multicolumn{3}{c}{ HDS } \\
\cline { 2 - 4 } & & $\begin{array}{c}\text { Lowest third } \\
\text { (\% of original) }\end{array}$ & $\begin{array}{c}\text { Middle third } \\
(\% \text { of original) }\end{array}$ & $\begin{array}{c}\text { Highest third } \\
(\% \text { of original) }\end{array}$ \\
\hline \multirow{2}{*}{ HDI } & Lowest third & $438(55.8)$ & $279(35.5)$ & $68(8.7)$ \\
& Middle third & $62(17.0)$ & $187(51.2)$ & $116(31.8)$ \\
Highest third & $1(0.3)$ & $63(19.4)$ & $261(80.3)$ \\
\hline
\end{tabular}

approximately half of the variation in one score is explained by variation in the other. We explored the agreement between the two scores further by tabulating the number of people in thirds of the modified score against the number of people in thirds of the original score. These data are shown in Table 3. While $44.2 \%$ of those in the lowest third of the original score were not in the lowest third of the modified score, only $8.7 \%$ of those in the lowest third on the original score were in the highest third for the modified score. Also, of the $19.7 \%$ of subjects in the highest third of the original score not in the highest third of the modified score, only one person was in the lowest third of the modified score.

Three of the original items from the HDI were modified for the HDS (polyunsaturated fatty acids (PUFA) as a percentage of energy intake, fibre and cholesterol), and three new items were added (fish, red meat and calcium). Table 4 shows positive correlations between the original and modified items for cholesterol $(r=0.65)$ and fibre $(r=0.13)$. For the PUFA item there was an inverse association $(r=-0.52)$. Compared with $82.2 \%$ for the

Table 4 Examining the impact of three items (PUFA as a percentage of energy intake, fibre and cholesterol) with cut-off points modified for the HDS

\begin{tabular}{lc}
\hline PUFA item & \\
\% scoring 1 & 82.2 \\
Original & 37.1 \\
Modified & -0.52 \\
$r$ original vs. modified & \\
Fibre item & \\
\% scoring 1 & 16.1 \\
Original & 49.1 \\
Modified & 0.13 \\
$r$ original vs. modified & \\
Cholesterol item & \\
\% scoring 1 & 62.2 \\
Original & 40.9 \\
Modified & 0.65 \\
$r$ original vs. modified & \\
$r$ HDS vs. HDI & 0.85 \\
No items modified & 0.78 \\
PUFA modified (HDS) & 0.81 \\
Fibre modified (HDS) & 0.83 \\
Cholesterol modified (HDS) & 0.73 \\
PUFA and fibre modified (HDS) & 0.75 \\
PUFA and cholesterol modified (HDS) & 0.79 \\
Fibre and cholesterol modified (HDS) & \\
&
\end{tabular}

PUFA - polyunsaturated fatty acids; HDS - Healthy Diet Score; HDI Healthy Diet Indicator. 
original PUFA item, only $37.1 \%$ of the sample scored 1 with the modified item. Corresponding figures were 16.1 vs. $49.1 \%$ and 62.2 vs. $40.9 \%$ for fibre and cholesterol, respectively. Agreement between the HDI and HDS with PUFA, fibre and cholesterol not modified and the three additional items (fish, red meat and calcium) included was 0.85 . Modifying the PUFA and fibre items had the greatest effect on the score (Table 4). With a correlation of 0.71 between the HDI and the fully modified HDS (see above), removing one or more of the three new items had little effect on agreement between the two scores $(r=0.70-0.75)$.

\section{Association between individual diet items and the HDS}

To examine the association between the items in the score and the overall score, we calculated Spearman's rank correlations between individual items and the total score. Table 5 shows that, in general, correlations were similar for men and women. Items with the strongest association with total score were percentage energy from saturated fatty acids and carbohydrates, and intakes of dietary fibre, fruit and vegetables, and meat and meat products. Higher percentage energy from saturated fatty acids and consumption of red meat/meat products were moderately correlated with lower HDS $(r=-0.57$ and -0.46 , respectively, for all subjects). Dietary fibre, fruit and vegetable consumption, and percentage energy from carbohydrates were moderately associated with higher HDS ( $r=0.58,0.54$ and 0.51 , respectively).

\section{Weighting of individual dietary components}

One concern when we decided on the adapted score was that by following current recommendations it gave insufficient weight to potentially protective dietary constituents such as fruit and vegetables and antioxidants.
We explored this issue by looking at how well the score discriminated between people with high and low intakes of fruit and vegetables and potentially protective micronutrients (vitamins $\mathrm{C}$ and $\mathrm{E}, \boldsymbol{\beta}$-carotene). We examined the distribution of intakes of vitamin $\mathrm{C}$, vitamin $\mathrm{E}$ and $\beta$-carotene across quartiles of the index. This showed reasonably strong linear trends. Median vitamin $\mathrm{C}$ intake was $105.7,142.5,161.0$ and $182.7 \mathrm{mg} \mathrm{day}^{-1}$ across quartiles of increasing diet quality. For vitamin $\mathrm{E}$, the trend was 8.0, 10.0, 10.4 and $11.0 \mathrm{mg} \mathrm{day}^{-1}$; and for $\beta$-carotene 3055.5, $3771.9,4151.4$ and $4581.8 \mu \mathrm{g} \mathrm{day}^{-1}$. We also looked at the extent to which other measures included in the score capture fruit and vegetable intake. The score for dietary fibre also gave an indication of fruit and vegetable intake. The proportions of subjects in the highest quartile of fruit and vegetable consumption across quartiles of increasing dietary fibre intake were $0.3,7.9,27.5$ and $64.4 \%$, respectively.

\section{Discussion}

We have shown that the selection of validated healthy diet scores for epidemiological studies presents problems and that modifications to an existing score result in a similar but different score. Should we have adapted our score to take account of new knowledge or should we have used the original score ${ }^{14}$ as unchanged as our data would allow? We felt the changes were justifiable and reasonable, as it meant the score more closely reflected current dietary recommendations ${ }^{32,33}$, but it did mean that the score we ultimately used was considerably different from the validated one we first selected. The new score had some similarity to the old score with a correlation coefficient of about 0.70; however, it follows that (based on the square of the correlation, i.e. the $R^{2}$ statistic) only about $50 \%$ of

Table 5 Spearman's rank correlation coefficients between increasing intake of individual items included in the modified Healthy Diet Score (HDS) and total score

\begin{tabular}{|c|c|c|c|}
\hline \multirow[b]{2}{*}{ Index items } & \multicolumn{3}{|c|}{$\begin{array}{l}\text { Correlation of daily intake } \\
\text { of index items with total HDS }\end{array}$} \\
\hline & All & Men & Women \\
\hline 1. Saturated fatty acids (\% energy intake) & -0.57 & -0.53 & -0.60 \\
\hline (Saturated fatty acids $(g)$ & -0.28 & -0.24 & $-0.30)$ \\
\hline 2. Polyunsaturated fatty acids (\% energy intake) & 0.14 & 0.19 & 0.11 \\
\hline (Polyunsaturated fatty acids (g) & -0.07 & -0.05 & $-0.08)$ \\
\hline 3. Protein (\% energy intake) & -0.07 & -0.11 & -0.07 \\
\hline (Protein $(g)$ & 0.09 & 0.09 & $0.10)$ \\
\hline 4. Total carbohydrates (\% energy intake) & 0.51 & 0.46 & 0.54 \\
\hline (Total carbohydrates $(g)$ & 0.29 & 0.29 & $0.28)$ \\
\hline 5. Dietary fibre $(\mathrm{g})$ & 0.58 & 0.56 & 0.58 \\
\hline 6. Fruit and vegetables $(\mathrm{g})$ & 0.54 & 0.52 & 0.54 \\
\hline 7. Pulses and nuts $(\mathrm{g})$ & 0.27 & 0.28 & 0.29 \\
\hline 8. Total non-milk extrinsic sugars (\% total energy intake) & -0.15 & -0.13 & -0.17 \\
\hline 9. Cholesterol (mg) & -0.29 & -0.25 & -0.31 \\
\hline 10. Fish $(g)$ & 0.34 & 0.32 & 0.35 \\
\hline 11. Red meat and meat products $(\mathrm{g})$ & -0.46 & -0.44 & -0.46 \\
\hline 12. Calcium (mg) & 0.10 & 0.10 & 0.10 \\
\hline (Energy intake (MJ) & 0.11 & 0.12 & 0.11) \\
\hline
\end{tabular}


the variation in the new score was explained by variation in the old score. The addition of new items had little effect on the agreement between the original HDI and the modified HDS; however, subtle changes to the cut-off points on which three items were based had greater impact. The modified HDS captured variability in dietary constituents for which there is strong evidence of protective effects against disease, such as consumption of fruits and vegetables and vitamin $\mathrm{C}$ intake.

A number of investigators have derived or adapted scores for use in epidemiological studies or in population surveillance ${ }^{16,17}$ but only a few have described how the process by which they produced their score relates to or improves on previous scores ${ }^{6}$. Our experience of adapting an existing score suggests that the justification, process and results of modification should be reported. Distributions of the scores may differ in younger populations but it is beyond the scope of these analyses to test this assumption. It would be valuable to know whether our experience with one diet score in a UK population of adults in early old age generalises to different scores used in diverse populations of different ages. The construction of healthy diet scores is more complicated than often assumed. The problems in identifying a suitable score stem partly from the inherent difficulty of deriving diet scores and partly from the lack of standard approaches employed to create and validate scores. These scores implicitly apply a complex series of weights to different components of the diet. The choice of items and their weighting should be based on empirical evidence of health benefits. The presence or absence of other dietary constituents may modify the health effects of dietary constituents. Therefore inclusion of interaction terms to weight foods in relation to intakes of other foods might be useful. Unfortunately, the knowledge required to derive such a score is either unavailable or incomplete.

As there is no 'best score' available, a consistent approach is required to replace the current plethora of scores $^{14,16-19,22,25}$. We would suggest that a score for common use (based on current recommendations such as those produced by COMA and WHO) needs to be created and tested in a number of prospective datasets to derive robust weightings that best predict subsequent health. This score would need to be easily obtainable from most nutritional datasets, to avoid the need for modification leading to an ambiguous score which may or may not have the predictive characteristics of the original. Such a score would allow comparison of the diets between populations ${ }^{17,35}$, within populations over time, and study of the associates and determinants of a healthy diet within populations. Validated scores would need to be designed for other groups such as children and for other populations such as those in developing countries. Until such scores are derived and validated, all authors using dietary scores should expect to describe the details of, and the rationale and justification for, their methods.

\section{Acknowledgements}

We would like to thank Professors George Davey Smith and Stephen Frankel for establishing the Boyd Orr cohort follow-up study; Walter Duncan, honorary archivist to the Rowett Research Institute, for helping us access the original research records; and Pauline Emmett for nutritional advice. We also wish to acknowledge all the research workers and subjects who participated in the original survey in 1937-39. This work was funded by Research into Ageing and the Economic and Social Research Council.

\section{References}

1 Block G. Epidemiologic evidence regarding vitamin C and cancer. American Journal of Clinical Nutrition 1991; 54: $1310 \mathrm{~S}-4 \mathrm{~S}$.

2 Ascherio A, Rimm EB, Giovannucci E, Speigelman D, Stampfer MJ, Willett WC. Dietary fat and risk of coronary heart disease in men: cohort follow up study in the United States. British Medical Journal 1996; 313: 84-90.

3 Hu FB, Stampfer MJ, Manson JE, Rimm E, Colditz GA, Rosner BA, et al. Dietary fat intake and the risk of coronary heart disease in women. New England Journal of Medicine 1997; 337: $1491-9$.

4 Hu FB. Dietary pattern analysis: a new direction in nutritional epidemiology. Current Opinion in Lipidology 2002; 13: 3-9.

5 Kant AK. Indexes of overall diet quality: a review. Journal of the American Dietetic Association 1996; 96: 785-91.

6 Dubois L, Girard M, Bergeron N. The choice of a diet quality indicator to evaluate the nutritional health of populations. Public Health Nutrition 2000; 3: 357-65.

7 Margetts BM, Campbell NA, Armstrong BK. Summarizing dietary patterns using multivariate analysis. Journal of Human Nutrition 1981; 35: 281-6.

8 Togo P, Heitman BL, Sorensen TIA, Osler M. Consistency of food intake factors by different dietary assessment methods and population groups. British Journal of Nutrition 2003; 90: $667-78$.

9 Hu FB, Rimm EB, Stampfer MJ, Ascherio A, Spiegelman D, Willett WC. Prospective study of major dietary patterns and risk of coronary heart disease in men. American Journal of Clinical Nutrition 2000; 72: 912-21.

10 Fung TT, Rimm EB, Spiegelman D. Association between dietary patterns and plasma biomarkers of obesity and cardiovascular risk. American Journal of Clinical Nutrition 2001; 73: 61-7.

11 Bell RA, Quant SA, Vitolins MZ, Arcury TA. Dietary patterns of older adults in a rural, tri-ethnic community: a factor analysis approach. Nutrition Research 2003; 23: 1379-90.

12 Quatromoni PA, Copenhafer DL, Demissie S, D'Agostino RB, O'Horo CE, Nam BH, et al. The internal validity of a dietary pattern analysis: the Framingham nutrition studies. Journal of Epidemiology and Community Health 2002; 56: 381-8.

13 Greenwood DC, Cade JE, Draper A, Barrett JH, Calvert C, Greenhalgh A. Seven unique food consumption patterns identified among women in the UK Women's Cohort Study. European Journal of Clinical Nutrition 2000; 54: 314-20.

14 Huijbregts P, Feskens E, Rasanen L, Fidanza F, Nissinen A, Menotti A, et al. Dietary patterns and 20 year mortality in elderly men in Finland, Italy, and The Netherlands: longitudinal cohort study. British Medical Journal 1997; 315: $13-7$.

15 Jacques PF, Tucker KL. Are dietary patterns useful for 
understanding the role of diet in chronic disease? American Journal of Clinical Nutrition 2001; 73: 1-2.

16 Dynesen AW, Haraldsdottir J, Holm L, Astrup A. Sociodemographic differences in dietary habits described by food frequency questions. European Journal of Clinical Nutrition 2003; 57: 1586-97.

17 Kim S, Haines PS, Siega-Riz A-M, Popkin BM. The Diet Quality Index-International (DQI-I) provides an effective tool for cross-national comparison of diet quality as illustrated by China and the United States. Journal of Nutrition 2003; 133: 3476-84.

18 Fitzgerald AL, Maclean DR, Veugelers PJ. Dietary reference intakes: a comparison with the Nova Scotia Nutrition Survey. Canadian Journal of Dietetic Practice and Research 2002; 63: $176-83$.

19 Haines PS, Siega-Riz A-M, Popkin BM. The Diet Quality Index Revised: a measurement instrument for populations Journal of the American Dietetic Association 1999; 99: 697-704.

20 Neuhouser ML, Patterson RE, King IB, Horner NK, Lampe JW. Selected nutritional biomarkers predict diet quality. Public Health Nutrition 2003; 6: 703-9.

21 Newby PK, Hu FB, Rimm EB, Smith-Warner SA, Feskanich D, Sampson L, et al. Reproducibility and validity of the Diet Quality Index Revised as assessed by use of a food frequency questionnaire. American Journal of Clinical Nutrition 2003; 78: 941-9.

22 Seymour JD, Calle EE, Flagg EW, Coates RJ, Ford ES, Thun MJ. Diet quality index as a predictor of short-term mortality in the American Cancer Society Cancer Prevention Study II nutrition cohort. American Journal of Epidemiology 2003; 157: $980-8$.

23 Fitzgerald AL, Maclean DR, Veugelers PJ. Diet quality and cancer incidence in Nova Scotia, Canada. Nutrition and Cancer 2002; 43: 127-32.

24 Kant AK, Schatzkin A, Graubard BI, Schairer C. A prospective study of diet quality and mortality in women. Journal of the American Medical Association 2000; 283: 2109-15.

25 McCullough ML, Feskanich D, Rimm EB, Giovannucci EL, Ascherio A, Variyam JN, et al. Adherence to the Dietary
Guidelines for Americans and risk of major chronic disease in men. American Journal of Clinical Nutrition 2000; 72 : $1223-31$.

26 Trichopoulou A, Kouris-Blazos A, Wahlqvist ML, Gnardellis C, Lagiou P, Polychronopoulos E, et al. Diet and overall survival in elderly people. British Medical Journal 1995; 311: $1457-60$.

27 Juni P, Witschi A, Bloch R, Egger M. The hazards of scoring the quality of clinical trials for meta-analysis. Journal of the American Medical Association 1999; 282: 1054-60.

28 Gunnell DJ, Frankel S, Nanchahal K, Braddon FEM, Davey Smith G. Lifecourse exposure and later disease: a follow-up study based on a survey of family diet and health in pre-war Britain. Public Health 1996; 110: 85-94.

29 Bingham SA, Gill C, Welch A, Cassidy A, Runswick SA, Oakes $\mathrm{S}$, et al. Validation of dietary assessment methods in the UK arm of EPIC using weighed records, and 24-hour urinary nitrogen and potassium and serum vitamin $\mathrm{C}$ and carotenoids as biomarkers. International Journal of Epidemiology 1997; 26: S137-51.

30 Ministry of Agriculture, Fisheries and Food. Food Portion Sizes. London: HMSO, 1993.

31 Royal Society of Chemistry and Ministry of Agriculture, Fisheries and Food. McCance \& Widdowson's The Composition of Foods. London: HMSO, 1991.

32 Department of Health. Nutritional Aspects of the Development of Cancer. Report on Health and Social Subjects No. 48. London: HMSO, 1998.

33 Department of Health. Nutritional Aspects of Cardiovascular Disease. Report on Health and Social Subjects No. 46. London: HMSO, 1994.

34 World Health Organization (WHO). Diet, Nutrition and Prevention of Chronic Diseases. Report of a WHO Study Group. Technical Report Series No. 797. Geneva: WHO, 1990.

35 Haveman-Nies A, Tucker KL, de Groot LCP, Wilson PWF, van Staveren WA. Evaluation of dietary quality in relationship to nutritional and lifestyle factors in elderly people of the US Framingham Heart Study and the European SENECA study. European Journal of Clinical Nutrition 2001; 55: 870-80. 